\title{
REVIEW
}

\section{High resolution satellite imaging sensors for precision agriculture}

\author{
Chenghai YANG (凶)
}

United States Department of Agriculture, Agricultural Research Service, Aerial Application Technology Research Unit, College Station, TX 77845, USA

\begin{abstract}
The central concept of precision agriculture is to manage within-field soil and crop growth variability for more efficient use of farming inputs. Remote sensing has been an integral part of precision agriculture since the farming technology started developing in the mid to late 1980 s. Various types of remote sensors carried on groundbased platforms, manned aircraft, satellites, and more recently, unmanned aircraft have been used for precision agriculture applications. Original satellite sensors, such as Landsat and SPOT, have commonly been used for agricultural applications over large geographic areas since the 1970s, but they have limited use for precision agriculture because of their relatively coarse spatial resolution and long revisit time. Recent developments in high resolution satellite sensors have significantly narrowed the gap in spatial resolution between satellite imagery and airborne imagery. Since the first high resolution satellite sensor IKONOS was launched in 1999, numerous commercial high resolution satellite sensors have become available. These imaging sensors not only provide images with high spatial resolution, but can also repeatedly view the same target area. The high revisit frequency and fast data turnaround time, combined with their relatively large aerial coverage, make high resolution satellite sensors attractive for many applications, including precision agriculture. This article will provide an overview of commercially available high resolution satellite sensors that have been used or have potential for precision agriculture. The applications of these sensors for precision agriculture are reviewed and application examples based on the studies conducted by the author and his collaborators are provided to illustrate how high resolution satellite imagery has been used for crop identification, crop yield variability mapping and pest management. Some challenges and future directions on the use of high resolution satellite sensors and other types of remote
\end{abstract}

Received November 30, 2017; accepted January 17, 2018

Correspondence: chenghai.yang@ars.usda.gov sensors for precision agriculture are discussed.

Keywords high resolution satellite sensor, multispectral imagery, precision agriculture, spatial resolution, temporal resolution

\section{Introduction}

Precision agriculture started with the research and development of grid soil sampling, soil sensors, yield monitors, positioning systems, and variable rate technology in the mid to late 1980s. With advances in global positioning systems (GPS), geographic information systems (GIS), remote sensing and sensor technology, the agricultural community has witnessed a rapid growth of a new body of precision agriculture technologies since the $1990 \mathrm{~s}^{[1-4]}$. Overall, the adoption of precision agriculture is relatively slow and varies by technology type, but precision agriculture as a farming strategy is gradually changing the way farmers manage their fields ${ }^{[5,6]}$. Some technologies developed for precision agriculture have become standard practices in production agriculture. For example, yield monitors and automatic guidance systems are the two most widely adopted precision agriculture technologies by individual farmers today in the USA. Other technologies, such as GPS-based soil sampling, real-time crop and soil sensors, remote sensing and variable rate technology, have been used by some producers, crop consultants and agricultural dealers for site-specific applications of fertilizers, herbicides, fungicides, water, seeds and lime. The central concept of precision agriculture is to identify within-field variability and manage that variability. More specifically, precision agriculture employs a suite of electronic sensors and spatial information technology (i.e., GPS, GIS and remote sensing) to map within-field soil and crop growth variability and to tailor farming inputs (e.g., fertilizers, pesticides, seeds and water) to the specific conditions in each area of a field with the aim to increase farm profits and reduce environmental impacts. 
Remote sensing applications in precision agriculture have been steadily increasing since the 1990s due to improvements in spatial, spectral and temporal resolutions of both airborne and satellite remote sensors. Airborne or satellite imagery allows a farmer to have an overhead view of the crops growing on the entire field or the entire farm. In addition to numerous ground-based soil and crop sensors, remote sensing imagery has become a major data source for documenting soil and crop growth variability because it provides a continuous view of all fields in the imaging area. Mulla ${ }^{[7]}$ reviewed the key advances of remote sensing in precision agriculture and the remaining knowledge gaps.

Images from the original remote sensing satellites, such as Landsat and SPOT, have long been used to monitor crop growing conditions, identify crop types and estimate crop yields over large geographic areas for agricultural applications ${ }^{[8-12]}$. However, this type of imagery has limited use for assessing within-field crop growth variability for precision agriculture because of its coarse spatial resolution and long revisit time. Therefore, airborne imaging systems have been widely used for precision agriculture since the 1990s. Among the advantages of airborne imaging systems are their relatively low cost, high spatial resolution, and real-time/near-real-time availability of images for visual assessment, and their ability to obtain data in narrow spectral bands in the visible, near-infrared (NIR), and shortwave infrared (SWIR) portions of the electromagnetic spectrum ${ }^{[13,14]}$.

Airborne imaging sensors can be categorized as multispectral and hyperspectral based on the number of spectral bands and band widths. Multispectral imaging sensors typically measure reflected or emitted energy in 3-12 different spectral bands. In contrast, hyperspectral imaging sensors measure radiation in tens to hundreds of narrow spectral bands across the electromagnetic spectrum. Images produced from hyperspectral sensors contain considerably more spectral detail than images from multispectral sensors and have a great potential to detect subtle differences between similar ground objects and features. Moran et al. ${ }^{[15]}$ reviewed some of the applications and addressed the potential of image-based remote sensing to provide spatially and temporally distributed information for precision agriculture applications.

Airborne multispectral imagery has been widely used in precision agriculture for assessing soil variability ${ }^{[16]}$, mapping crop growth and yield variability ${ }^{[17-19]}$, detecting crop insect infestations and disease infections ${ }^{[20,21]}$ and mapping water status ${ }^{[22]}$. Airborne hyperspectral imagery has also been evaluated for assessing soil fertility ${ }^{[23]}$, mapping crop yield variability ${ }^{[24-26]}$ and detecting crop pests $^{[27-30]}$.

Advances in high resolution satellite sensors have significantly narrowed the gap in spatial resolution between the original satellite imagery and airborne imagery. When the IKONOS satellite was successfully launched into orbit in 1999, it made history with the first high resolution commercial remote sensing satellite. IKONOS provided multispectral data in three visible bands and one NIR band with 3.28-m resolution at nadir. Two years later, QuickBird was launched to deliver multispectral images with $2.62-\mathrm{m}$ resolution at nadir in four spectral bands similar to those of IKONOS. Until 2008, when GeoEye-1 was launched to provide finer image data, IKONOS and QuickBird offered industry-leading panchromatic and four-band multispectral imagery.

Following the success of IKONOS and QuickBird, numerous commercial high resolution satellite sensors have become available. Remote sensing from space is rapidly changing with many countries and commercial firms developing and launching new satellite imaging systems. Over the last few years, the world has seen a proliferation in the launch of high resolution imaging satellites. Most of these satellites offer multispectral imagery with resolutions from 1.24 to $4 \mathrm{~m}$, including, in chronological order, KOMPSAT-2, GeoEye-1, WorldView-2, Pléiades-1A, KOMPSAT-3, Pléiades-1B, SkySat-1, SkySat-2, WorldView-3, Gaofen-2, KOMPSAT-3A, TripleSat, and WorldView-4, Cartosat-2C, GaoJing-1 01/ 02 and Cartosat-2D. Other sensors offer multispectral imagery with spatial resolutions from 5 to $10 \mathrm{~m}$, including SPOT 5, Rapideye, SPOT 6, SPOT 7, Sentinel-2A, Sentinel-2B and several others.

These imaging sensors not only provide images with high spatial resolution, but also can repeatedly view the same target area. The high revisit frequency and fast data turnaround time combined with their relatively large aerial coverage make high resolution satellite sensors attractive for many applications, including precision agriculture. In the next section, details about these satellite sensors will be given. In Section 3, their applications in precision agriculture will be discussed and application examples are provided to illustrate how high resolution satellite imagery has been used for crop identification, mapping crop yield variability and pest management. In the last section, some challenges and future trends on the use of high resolution satellite sensors and other remote sensors for precision agriculture are discussed. Some of the advantages and limitations of the use of different types of remote sensing imagery for precision agriculture are also discussed.

\section{High resolution satellite sensors}

\subsection{Sensors with spatial resolutions of $5 \mathrm{~m}$ or finer}

Table 1 summarizes most of the high resolution satellite sensors that have been launched since 1999 with spatial resolutions of $5 \mathrm{~m}$ or finer in multispectral bands. All the 
Table 1 High resolution satellite sensors with spatial resolutions of $5 \mathrm{~m}$ or finer in multispectral bands

\begin{tabular}{|c|c|c|c|c|c|c|}
\hline Sensor name & Year launched & Number of multispectral bands ${ }^{\mathrm{a}}$ & Multispectral pixel size $/ \mathrm{m}$ & $\begin{array}{l}\text { Panchromatic } \\
\text { pixel size } / \mathrm{m}\end{array}$ & $\begin{array}{l}\text { Radiometric } \\
\text { resolution/bit }\end{array}$ & Revisit time/d \\
\hline$\overline{\mathrm{IKONOS}}$ & $1999^{c}$ & 4 & 3.28 & 0.82 & 11 & 3 \\
\hline QuickBird & $2001^{\mathrm{c}}$ & 4 & 2.62 & 0.65 & 11 & $1-3.5$ \\
\hline KOMPSAT-2 & 2006 & 4 & 4 & 1 & 10 & 1 \\
\hline GeoEye-1 & 2008 & 4 & $1.65(1.84)^{\mathrm{d}}$ & $0.41(0.46)^{\mathrm{d}}$ & 12 & 3 \\
\hline WorldView-2 & 2009 & $8^{e}$ & 1.84 & 0.46 & 11 & $1.1-3.7$ \\
\hline Pléiades-1A & 2011 & 4 & 2 & 0.5 & 12 & 1 \\
\hline KOMPSAT-3 & 2012 & 4 & 2.8 & 0.7 & 14 & 1 \\
\hline Pléiades-1B & 2012 & 4 & 2 & 0.5 & 12 & 1 \\
\hline SkySat-1 & 2013 & 4 & 2 & 0.9 & 10 & 1 \\
\hline SkySat-2 & 2014 & 4 & 2 & 0.9 & 10 & 1 \\
\hline WorldView-3 & 2014 & $28^{\mathrm{f}}$ & 1.24 & 0.31 & 11 & $1-4.5$ \\
\hline Gaofen-2 & 2014 & 4 & 3.2 & 0.8 & 14 & 5 \\
\hline KOMPSAT-3A & 2015 & $5^{g}$ & 2.2 & 0.55 & 14 & 1 \\
\hline TripleSat & 2015 & 4 & 3.2 & 0.8 & 10 & 1 \\
\hline WorldView-4 & 2016 & 4 & 1.24 & 0.31 & 11 & $1-4.5$ \\
\hline Cartosat-2C & 2016 & 4 & 2 & 0.65 & 11 & 7 \\
\hline GaoJing-1 01/02 & 2016 & 4 & 2 & 0.5 & 11 & 4 \\
\hline Cartosat-2D & 2017 & 4 & 2 & 0.65 & 11 & 7 \\
\hline
\end{tabular}

Note: ${ }^{\mathrm{a}}$ All sensors except the ones with a superscript have four standard spectral bands (blue, green, red and near-infrared); ${ }^{\mathrm{b}}$ at nadir; ${ }^{\mathrm{c}}$ retired in $2015 ;{ }^{\mathrm{d}}$ orbit altitude was raised in 2013; ${ }^{\mathrm{e}}$ eight spectral bands (coastal, blue, green, yellow, red, red edge, near-infrared 1 and near-infrared 2); ${ }^{\mathrm{f}}$ the same eight spectral bands as WorldView2 at $1.24 \mathrm{~m}$, eight shortwave bands at $3.7 \mathrm{~m}$ and 12 CAVIS bands at $30 \mathrm{~m}$ for improved atmospheric corrections for clouds, aerosols, vapors, ice and snow; ${ }^{\mathrm{g}}$ four standard spectral bands at $2.2 \mathrm{~m}$ and one mid-wave infrared at $5.5 \mathrm{~m}$.

sensors listed in the table contain a panchromatic band, which has a much higher spatial resolution than the corresponding multispectral bands.

\subsubsection{IKONOS}

IKONOS was the first high resolution satellite sensor launched into space on September 24, 1999. It provided $0.82-\mathrm{m}$ panchromatic images in the $450-900 \mathrm{~nm}$ spectral range and 3.28-m multispectral imagery in the blue (450$520 \mathrm{~nm})$, green $(510-600 \mathrm{~nm})$, red $(630-700 \mathrm{~nm})$ and NIR $(760-850 \mathrm{~nm})$ bands. The panchromatic and multispectral imagery can be merged to create 1-m color imagery (pansharpened). The radiometric resolution was 11 bits and the image swath was $11.3 \mathrm{~km}$ at nadir. IKONOS was originally owned by Space Imaging and then acquired by GeoEye, Inc. (Herndon, VA, USA) to become part of its constellation of high resolution satellites. GeoEye was merged into DigitalGlobe, Inc. (Longmont, CO, USA) on January 29, 2013. IKONOS was deactivated on March 31, 2015, but archived IKONOS images remain available.

\subsubsection{QuickBird}

QuickBird, the second commercial high resolution satel- lite, was launched by DigitalGlobe on October 18, 2001. QuickBird provided panchromatic and multispectral data in essentially the same spectral ranges as those of IKONOS, but at finer spatial resolutions: $0.6-\mathrm{m}$ for panchromatic data and 2.4-m for multispectral data. Pixel depth was 11 bits, but the image swath at nadir was wider at $16.4 \mathrm{~km}$ and the sensor can tilt up to $45^{\circ}$ off-nadir. QuickBird was deactivated in early 2015.

\subsubsection{KOMPSAT-2, -3 and -3 A}

In addition to DigitalGlobe's constellation, many other companies have launched their constellations of high resolution satellites. KOMPSAT-2, also referred to as Arirang-2, was developed and launched by the Korea Aerospace Research Institute, Daejeon, South Korea on July 28, 2006. KOMPSAT- 2 acquires 1-m panchromatic imagery and 4-m multispectral imagery in blue, green, red and NIR bands. KOMPSAT-3, launched on May 17, 2012, is capable of $0.7-\mathrm{m}$ panchromatic and 2.8-m multispectral resolution. As a sister spacecraft to KOMPSAT-3, KOMPSAT-3A was launched on March 25, 2015 to provide $0.55-\mathrm{m}$ resolution in the panchromatic band, 2.2$\mathrm{m}$ resolution in the four standard spectral bands and $5.5-\mathrm{m}$ resolution in an additional mid-wave infrared band (3.3$5.2 \mu \mathrm{m})$. 


\subsubsection{GeoEye-1}

On September 6, 2008, GeoEye launched GeoEye-1, the first of its second-generation high resolution satellites after IKONOS. This satellite offers unprecedented spatial resolution by simultaneously acquiring $0.41-\mathrm{m}$ panchromatic and $1.65-\mathrm{m}$ four-band multispectral (i.e., blue, green, red and NIR) imagery with a revisit time of less than 3 days. The spectral ranges are similar to those of IKONOS. The pixel dynamic range is also 11 bits. The image swath is increased to $15.2 \mathrm{~km}$. During late summer of 2013, the orbit altitude of the GeoEye-1 satellite sensor was raised from 680 to $770 \mathrm{~km}$. As a result, the nadir spatial resolutions of GeoEye- 1 were changed to $0.46 \mathrm{~m}$ for panchromatic data and $1.84 \mathrm{~m}$ for multispectral data. GeoEye became part of DigitalGlobe in January 2013.

\subsubsection{WorldView-2, -3 , and -4}

WorldView-2, launched into space on October 8, 2009, was the most technologically-advanced high resolution satellite ever launched before its twin, WorldView-3, reached orbit. WorldView-2 collects $0.46-\mathrm{m}$ panchromatic data in $450-800 \mathrm{~nm}$ and $1.85-\mathrm{m}$ multispectral imagery in eight visible to NIR (VNIR) spectral bands: coastal (400$450 \mathrm{~nm})$, blue $(450-510 \mathrm{~nm})$, green $(510-580 \mathrm{~nm})$, yellow $(585-625 \mathrm{~nm})$, red $(630-690 \mathrm{~nm})$, red edge $(705-745 \mathrm{~nm})$, NIR $1(770-895 \mathrm{~nm})$ and NIR $2(860-1040 \mathrm{~nm})$. Its unique combination of high spatial and spectral resolution provides new opportunities and potential for a variety of practical remote sensing applications. WorldView-2 images are distributed at either $0.5-$ or $0.6-\mathrm{m}$ resolution for the panchromatic band and at either 2- or 2.4-m resolution for the multispectral bands, depending on the viewing angle of the sensor. The image swath at nadir is $16.4 \mathrm{~km}$ and the average revisit time is 1.1 days.

WorldView-3, launched on August 13, 2014, is the more sophisticated twin of DigitalGlobe's WorldView-2. WorldView-3 collects panchromatic data at $0.31 \mathrm{~m}$, the same eight VNIR spectral bands as WorldView-2 at $1.24 \mathrm{~m}$, eight SWIR bands (1195-2365 $\mathrm{nm}$ ) at $3.7 \mathrm{~m}$ and 12 CAVIS bands (405-2245 $\mathrm{nm})$ at $30 \mathrm{~m}$ for improved atmospheric corrections for clouds, aerosols, vapors, ice and snow (CAVIS) with an average revisit time of less than one day. Due to US government regulations, SWIR data are currently only provided at $7.5-\mathrm{m}$ resolution. Not only is WorldView-3 the highest resolution satellite ever launched, it features one panchromatic band and 28 multispectral bands of remotely sensed data. The high resolution panchromatic and multispectral bands, which have the same spectral ranges as those of WorldView-2, are ideal for visual analysis and plant health assessments. The eight SWIR bands are ideal for mineral and hydrocarbon exploration and 12 CAVIS bands are ideal for improved atmospheric corrections for clouds, aerosols, vapors, ice and snow (CAVIS).

WorldView-4, previously known as GeoEye-2, was launched on November 11, 2016. WorldView-4 provides $0.31-\mathrm{m}$ panchromatic and 1.24-m four-band multispectral imagery with a revisit time of less than one day. As the satellite started its life as GeoEye-2 and was later renamed, WorldView-4 has the same spectral bands as GeoEye-1 and similar spatial resolutions as WorldView-3. WorldView-3 and 4 currently offer the highest resolution satellite imagery with unmatched spectral bands and collection times.

\subsubsection{Pléiades-1A and -1B}

Pléiades-1A and -1B are operated by Airbus Defense and Space in Toulouse, France. Pléiades-1A was launched on December 16, 2011. Joined by its twin, Pléiades-1B, in space on December 2, 2012, they provide 0.5-m panchromatic and 2-m four-band multispectral (i.e., blue, green, red and NIR) products with daily revisit time and $20-\mathrm{km}$ footprints. It should be noted that the native resolution of Pléiades- $1 \mathrm{~A}$ and $-1 \mathrm{~B}$ is $0.7-\mathrm{m}$ panchromatic and $2.8-\mathrm{m}$ multispectral before it is processed for delivery.

\subsubsection{SkySat-1 and -2}

SkySat-1 and -2 are the first two microsatellites built by Google's Terra Bella (formerly called Skybox Imaging) in Mountain View, CA, USA to collect high resolution panchromatic and multispectral images of Earth. The satellites operate in a polar inclined, circular orbit at approximately $450 \mathrm{~km}$ above Earth. SkySat-1 was launched on November 21, 2013, while SkySat-2 was launched on July 8,2014 . The optical imagery of each satellite covers a panchromatic band $(450-900 \mathrm{~nm})$ at $0.9 \mathrm{~m}$ and four multispectral channels (blue $450-515 \mathrm{~nm}$, green 515-595 nm, red 605-695 $\mathrm{nm}$ and NIR 740$900 \mathrm{~nm}$ ) at a resolution of $2 \mathrm{~m}$ at nadir. A ground swath of $8 \mathrm{~km}$ is covered at nadir. Stereo imaging is supported by the satellites. The sensor can also capture high-definition video in its panchromatic channel.

Terra Bella ultimately plans a 24-satellite constellation occupying four different polar-orbit planes that will provide high resolution imagery and full-motion video for commercial sale. SkySat-3, the third satellite of Terra Bella, was launched on June 22, 2016, and SkySat-4, -5, -6 and -7 were launched on September 16, 2016. More will be launched in the coming years. The company's goal is to be able to provide high resolution satellite imagery of any place on Earth multiple times a day. On February 3, 2017, Google announced that it would sell Terra Bella and its SkySat satellite constellation to Planet Laboratories, Inc. (San Francisco, CA, USA) and enter into a multi-year agreement to purchase SkySat imaging data. 


\subsubsection{Gaofen-2}

The Gaofen-2 satellite, designed and developed by the China Academy of Space Technology in Beijing, China, was launched on August 19, 2014. It is capable of collecting images with a ground sampling distance of $0.8 \mathrm{~m}$ in a panchromatic band and $3.2 \mathrm{~m}$ in four multispectral bands (i.e., blue, green, red and NIR) on a swath of $45 \mathrm{~km}$. It has a revisit time of five days. Gaofen-2 is one of the seven satellites in the China High-Resolution Earth Observation System constellation to be completed by 2020. So far, four Gaofen satellites have been launched with Gaofen-2 providing the highest resolution panchromatic and multispectral imagery. Gaofen-1 offers 2-m panchromatic and 8- and 16-m multispectral data, while Gaofen-3 provides multi-polarized C-band synthetic aperture radar data at meter-level resolution and Gaofen-4 covers a large imaging area with coarse spatial resolution and high temporal resolution.

\subsubsection{TripleSat}

The TripleSat constellation, built by Surrey Satellite Technology Ltd., Guildford, UK, was launched on July 10, 2015. TripleSat consists of three identical satellites in the same orbital plane exactly $120^{\circ}$ apart, making it possible to target anywhere on earth once per day. The TripleSat constellation delivers $0.8-\mathrm{m}$ visible panchromatic $(450-650 \mathrm{~nm})$ and 3.2-m four-band multispectral images with a $24-\mathrm{km}$ swath.

\subsubsection{Cartosat-2C and -2D}

Following the successful launch of Cartosat-2, -2A and -2B to provide panchromatic data, the Indian Space Research Organization launched Cartosat-2C and $-2 \mathrm{D}$ on June 22, 2016 and February 15, 2017, respectively. The two satellites carry identical sensors to provide $0.65-\mathrm{m}$ panchromatic data and 2-m multispectral data in the four standard spectral bands. Cartosat-2E carrying the sane sensors is planned to be launched in 2017.

\subsubsection{GaoJing-1 01/02}

GaoJing-1, also known as SuperView-1, is a constellation of Chinese civilian remote sensing satellites operated by Beijing Space View Tech Co. Ltd. The first pair of satellites was launched on December 28, 2016. These satellites are spaced at $180^{\circ}$ on the same orbit to provide images with $0.5-\mathrm{m}$ panchromatic resolution and $2-\mathrm{m}$ multispectral resolution in the four standard spectral bands. A second pair of this type was launched in early 2018 , bringing the constellation to four satellites phased $90^{\circ}$ from each other on the same orbit.

\subsection{Sensors with spatial resolutions of 5-10 m}

Table 2 summarizes most of the high resolution satellite sensors with spatial resolutions of 5-10 $\mathrm{m}$ in multispectral bands. The three SPOT sensors also contain a panchromatic band.

\subsubsection{SPOT 5, 6, and 7}

In addition to Pléiades-1A and -1B, SPOT 5, 6, and 7 are operated by Airbus Defense and Space. SPOT 5 was placed into orbit on May 4, 2002 and decommissioned on March 31, 2015. It offered panchromatic data at 2.5-5 m and multispectral data at $10 \mathrm{~m}$ for the green, red and NIR bands and $20 \mathrm{~m}$ for the SWIR band $(1.58-1.75 \mu \mathrm{m})$. SPOT 5 covered $60 \mathrm{~km} \times 60 \mathrm{~km}$ or $60 \mathrm{~km} \times 120 \mathrm{~km}$ in twininstrument mode and provided an ideal balance between high resolution and wide-area coverage.

SPOT 6 was launched on September 9, 2012, while SPOT 7 was launched on June 30, 2014. SPOT 6 and 7 are capable of imaging the earth with a resolution of $1.5 \mathrm{~m}$ in a panchromatic band and a resolution of $6 \mathrm{~m}$ in four multispectral bands (i.e., blue, green, red and NIR). The imaging swath of the SPOT twins is $60 \mathrm{~km}$ at nadir. SPOT 6 and 7 are phased in the same orbit as Pléiades-1A and -1B at an altitude of $694 \mathrm{~km}$, forming a constellation of two-by-two satellites, $90^{\circ}$ apart from one another. They form a constellation of earth-imaging satellites designed to

Table 2 High resolution satellite sensors with spatial resolutions of 5-10 $\mathrm{m}$ in multispectral bands

\begin{tabular}{|c|c|c|c|c|c|c|}
\hline Sensor name & Year launched & Number of multispectral bands ${ }^{\mathrm{a}}$ & Multispectral pixel size $/ \mathrm{m}$ & $\begin{array}{l}\text { Panchromatic } \\
\text { pixel size } / \mathrm{m}\end{array}$ & $\begin{array}{l}\text { Radiometric } \\
\text { resolution/bit }\end{array}$ & Revisit time/d \\
\hline$\overline{\text { SPOT } 5}$ & $2002^{\mathrm{c}}$ & $4^{\mathrm{d}}$ & 10 & 2.5 & 8 & $2-3$ \\
\hline RapidEye & 2008 & $5^{\mathrm{e}}$ & 6.5 & N/A & 12 & $1-5.5$ \\
\hline SPOT 6 & 2012 & 4 & 6 & 1.5 & 12 & 1 \\
\hline SPOT 7 & 2014 & 4 & 6 & 1.5 & 12 & 1 \\
\hline Sentinel-2A & 2015 & $13^{\mathrm{f}}$ & 10 & N/A & 12 & 5 \\
\hline Sentinel-2B & 2017 & $13^{\mathrm{f}}$ & 10 & N/A & 12 & 5 \\
\hline
\end{tabular}

Note: ${ }^{\mathrm{a}}$ All sensors except the ones with a superscript have four standard spectral bands (blue, green, red and near-infrared) $;{ }^{\mathrm{b}}$ at nadir; ${ }^{\mathrm{c}}$ retired in $2015 ;{ }^{\mathrm{d}}$ three standard spectral bands (green, red and near-infrared) at $10 \mathrm{~m}$ and one shortwave infrared band at $20 \mathrm{~m} ;{ }^{\mathrm{e}}$ four standard spectral bands and one red edge band; ${ }^{\mathrm{f}}$ four standard spectral bands at $10 \mathrm{~m}$, six bands at $20 \mathrm{~m}$ and three bands at $60 \mathrm{~m}$. 
provide continuity of high resolution, wide swath data up to 2024. SPOT 6 and 7 cover wider areas with $1.5-\mathrm{m}$ resolution, while Pléiades-1A and $-1 \mathrm{~B}$ are focused on more targeted zones with a greater level of detail $(0.5 \mathrm{~m})$.

\subsubsection{RapidEye}

RapidEye, launched on August 29, 2008, is the constellation of five satellites currently owned and operated by Planet Laboratories. Each of RapidEye's five satellites contains identical sensors and travel on the same orbital plane at an altitude of $630 \mathrm{~km}$. The five satellites together are capable of collecting multispectral imagery in five spectral bands: blue $(440-510 \mathrm{~nm})$, green $(520-590 \mathrm{~nm})$, red (630-690 nm), red edge (690-730 nm) and NIR (760$880 \mathrm{~nm}$ ). The nominal resolution on the ground is $6.5 \mathrm{~m}$, but the imagery is resampled to $5 \mathrm{~m}$. The swath width is $77 \mathrm{~km}$ and revisit time is from daily off-nadir to 5.5 days at nadir. RapidEye's satellites are the first commercial satellites to include the red edge band, which is sensitive to changes in chlorophyll content.

\subsubsection{Sentinel-2A and -2B}

The Sentinel-2 mission comprises two polar-orbiting satellites in the same orbit, phased at $180^{\circ}$ to each other. The twin satellites, Sentinel-2A and -2B, were launched on June 23, 2015 and March 7, 2017, respectively. They are the first two optical Earth observation satellites in the European Copernicus program that were developed and built under the industrial leadership of Airbus Defense and Space for the European Space Agency. Sentinel-2A and -2B each offer 13 spectral bands in the 443-2190 nm range with four standard bands (i.e., blue, green, red and NIR) at a spatial resolution of $10 \mathrm{~m}$, four red edge bands and two SWIR bands at $20 \mathrm{~m}$, and three atmospheric correction bands at $60 \mathrm{~m}$. The orbital swath width is $290 \mathrm{~km}$. Revisit time is 5 days at the equator and 2-3 days at mid-latitudes with the twin satellites.

\subsubsection{Other satellite sensors}

Several other Chinese satellite sensors provide $10-\mathrm{m}$ multispectral imagery. TH-01, launched on August 24, 2010, collects 5-m triplet stereo images, 2-m panchromatic images and 10-m multispectral (i.e., blue, green, red and NIR) images. Launched on December 22, 2011, ZY-1 02C is equipped with a $5-\mathrm{m}$ panchromatic and $10-\mathrm{m}$ multispectral (i.e., green, red and NIR) scanner and a 2.36-m high resolution panchromatic scanner. SJ-9A, launched on October 14,2012 , is equipped with a $2.5-\mathrm{m}$ panchromatic and $10-\mathrm{m}$ multispectral scanner (i.e., blue, green, red and NIR). China-Brazil Earth Resources Satellite 4, launched on December 7, 2014, provides 5-m panchromatic and 10-m multispectral data and other coarser resolution image data.

ALOS (Advanced Land Observing Satellite) was launched by Japan Aerospace Exploration Agency on January 24, 2006. It is also known as Daichi, the Japanese name for Earth. ALOS was decommissioned on May 12, 2011. It provided $2.5 \mathrm{-m}$ panchromatic data and $10-\mathrm{m}$ multispectral data in the four standard bands. Following the launch of Resourcesat- 1 and -2 by the Indian Space Research Organization on October 17, 2003 and April 20, 2011, respectively, Resourcesat-2A was launched on December 7, 2016. All three satellites provide $5.8-\mathrm{m}$ multispectral data in green, red and NIR bands.

The above satellite imaging sensors constitute most of the current arena of high resolution satellite remote sensing. More and more satellite imaging sensors will be launched in the coming years. This is a very dynamic area that changes all the time. Imagery from most of the satellite sensors listed in Tables 1-2 can be ordered from various online sources. A tasking order can be made by defining a custom polygon on Earth to be imaged by the next available high resolution satellite. The area of interest (AOI) can be specified by WGS-84 latitude/longitude or UTM grid coordinates with zone number. The customer can upload the AOI in one of several file formats (txt, pdf, $\mathrm{kmz} / \mathrm{kml}$ or ESRI shapefile). Some websites allow the drawing of the AOI online. The time to collect the AOI is controlled by local weather conditions and competition from surrounding tasking orders. An archive order can also be made from a historic database of high resolution satellite images with specific dates.

\section{Applications of high resolution satellite sensors in precision agriculture}

IKONOS and QuickBird were the first high resolution satellite sensors that have been evaluated for diverse precision agricultural applications. Johnson et al. ${ }^{[31]}$ evaluated IKONOS multispectral imagery for mapping leaf area index for vineyard canopy management. Dobermann and Ping ${ }^{[32]}$ integrated IKONOS imagery with yield monitor data for improving the accuracy of yield maps. Sullivan et al. ${ }^{[33]}$ used IKONOS imagery to estimate surface soil property variability in two physiographic regions of Alabama. Ping et al. ${ }^{[34]}$ created soil organic matter maps using regression kriging that incorporated elevation, surface electrical conductivity and bare soil reflectance derived from IKONOS satellite images.

Yang et al. ${ }^{[35]}$ compared QuickBird imagery and airborne imagery for mapping grain sorghum yield patterns. Yang et al. evaluated QuickBird imagery for mapping cotton yield ${ }^{[36]}$ and for crop type identification $^{[37]}$. Franke and Menz ${ }^{[38]}$ evaluated QuickBird imagery for multi-temporal wheat disease detection. Shou et al. ${ }^{[39]}$ found that reflectance values from the individual visible spectral bands in QuickBird satellite images were highly 
correlated with winter wheat total $\mathrm{N}$ concentration and aboveground biomass. Bausch et al. ${ }^{[40]}$ determined correlations between QuickBird satellite data and agronomic parameters of irrigated maize grown in small plots. Song et al. ${ }^{[41]}$ delineated agricultural management zones with high resolution QuickBird imagery. Bausch and Khosla $^{[42]}$ compared QuickBird images with ground-based multispectral data for estimating nitrogen status of irrigated maize. Santoso et al. ${ }^{[43]}$ used QuickBird images to map and identify basal stem rot disease in oil palms. De Castro et al. ${ }^{[44]}$ evaluated QuickBird images for broad-scale cruciferous weed patch classification in winter wheat for in-season site-specific control.

SPOT-5 imagery with a coarser spatial resolution was available shortly after QuickBird was launched. Yang et al. evaluated SPOT 5 images for estimating crop yield ${ }^{[45]}$ and for crop type identification ${ }^{[46]}$. Söderström et al. ${ }^{[47]}$ predicted protein content in malting barley using proximal sensing and SPOT 5 images. Ghobadifar et al. ${ }^{[48]}$ developed an early warning system for brown planthopper (Nilaparvata lugens) in rice farming using SPOT 5 images. The 10-m SPOT 5 sensor was decommissioned in 2015, but the 6-m SPOT 6 and 7 sensors continue to provide images. Yuan et al. ${ }^{[49]}$ used SPOT 6 high resolution satellite images for mapping powdery mildew at a regional scale.

Other satellite sensors have also been used for various precision agriculture applications. Wagner and Hank ${ }^{[50]}$ evaluated the suitability of aerial and RapidEye satellite data for calculation of site-specific nitrogen fertilization compared to ground-based sensor data. Magney et al. ${ }^{[51]}$ mapped wheat nitrogen uptake from vegetation indices derived from RapidEye imagery. Bu et al. ${ }^{[52]}$ compared RapidEye satellite imagery and ground-based active optical sensors as yield predictors in sugar beet, spring wheat, corn, and sunflower. Gomez-Candon et al. ${ }^{[53]}$ assessed the errors in input prescription maps based on high spatial resolution GeoEye-1 images. Caturegli et al. ${ }^{[54]}$ compared GeoEye-1 satellite and ground-based multispectral data for estimating nitrogen status of turfgrasses. Li et al. ${ }^{[55]}$ studied the feasibility of Huanglongbing (citrus greening) detection based on WorldView-2 satellite images.

\subsection{Example 1: SPOT 5 imagery for crop type identification}

To illustrate how high resolution satellite images can be used for crop type identification, the work conducted by Yang et al. ${ }^{[46]}$ is used as an example. A SPOT 5 multispectral image scene covering a $60 \mathrm{~km} \times 60 \mathrm{~km}$ area in the Rio Grande Valley of south Texas was acquired on May 19, 2006. The imaging date was selected based on the crop calendar and the satellite availability for the area. The spatial resolution was $10 \mathrm{~m}$ for the green, red and NIR bands and $20 \mathrm{~m}$ for the SWIR band, which was resampled to 10 -m pixel size prior to delivery.

Two intensively-cropped areas covering a variety of crops with different growth stages were selected within the satellite image as the study sites. For this article, the results from the study site near Alamo, TX, USA are presented. The site covered an $11.2 \mathrm{~km} \times 8.5 \mathrm{~km}$ area with center coordinates of $\left(98^{\circ} 03^{\prime} 26^{\prime \prime} \mathrm{W}, 26^{\circ} 06^{\prime} 34^{\prime \prime} \mathrm{N}\right)$. Five supervised classification techniques, including minimum distance, Mahalanobis distance, maximum likelihood, spectral angle mapper (SAM) and support vector machine (SVM), were used.

Figure 1 shows the color-infrared (CIR) composite image and a five-class classification map from the fourband image based on maximum likelihood for the study site. The CIR composite reveals distinct differences between the crops and other cover types in the study area. On the CIR images, crops and other vegetation

(a)
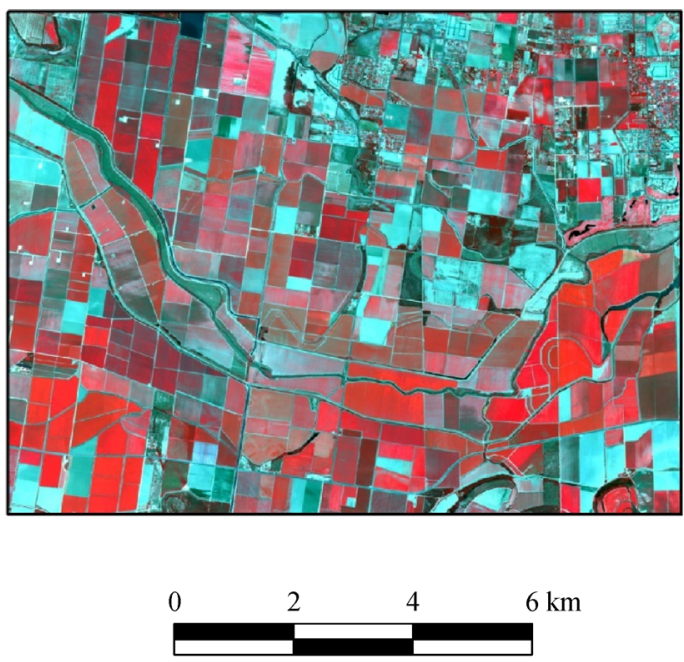

$\stackrel{N}{\Lambda}$

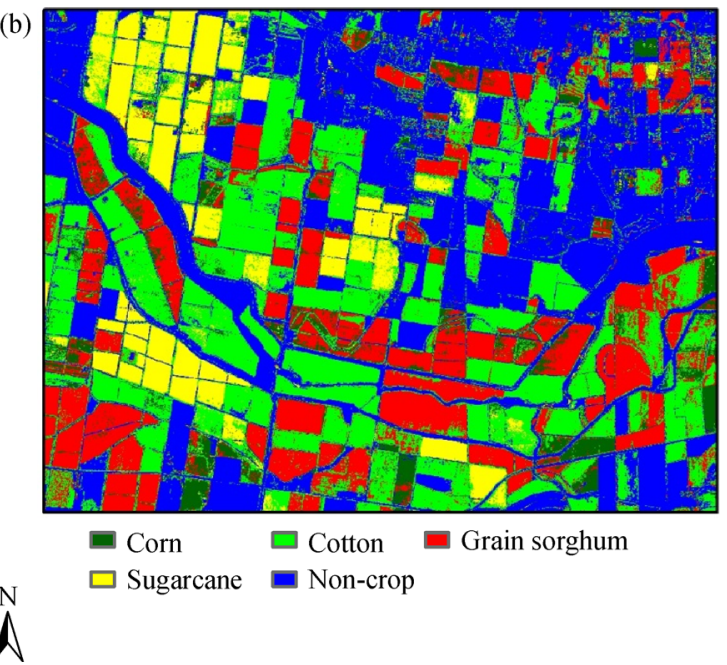

Fig. 1 SPOT 5 satellite color-infrared image (a) and five-class classification map (b) generated from the four-band SPOT 5 image based on maximum likelihood classification for an intensively-cropped area near Alamo, TX, USA 
generally have a reddish color, bare soil has a grayish and cyanish tone, and water has a dark or bluish color. At the time the image was acquired, corn was at milk to dough growth stages and grain sorghum was at boot to half-bloom stages. Cotton had reached the bloom stage and sugarcane was progressing through mid-season vegetative growth. All normal planted fields had reached $80 \%-100 \%$ canopy cover, though late planted fields for each crop had smaller plants and large soil exposure.

Visual comparison of the classification map and the CIR image indicates that the classification map provided good separations between the crop and non-crop classes. Most of the fields on the classification map had only one dominant class, but all fields contained small inclusions of other classes due to the within-field variability and the spectral similarities among some of the classes. Accuracy assessment showed that overall accuracy ranged from $72.2 \%$ for SAM to $91.0 \%$ for maximum likelihood for the site, indicating that $72 \%-91 \%$ of the pixels were correctly identified in the classification map using the five classification methods. Overall kappa varied from 0.622 to 0.875 among the five classifiers, indicating that the classification results agreed well with the reference data with one being a perfect agreement.

Kappa analysis showed that maximum likelihood and SVM were significantly better than the other three classifiers, but there was no significant difference between the two classifiers. Mahalanobis distance was significantly better than minimum distance and SAM, but there was no statistical difference between the two classifiers. As overall accuracy indicates the overall performance of a whole classification map, producer's accuracy and user's accuracy are more meaningful for the individual classes. The producer's and user's accuracies ranged from $71 \%$ to $98 \%$ among the five classes for the maximum likelihood-based classification map.

To simulate coarser resolution satellite imagery and examine the effect of pixel size on classification results, the $10-\mathrm{m}$ image was aggregated to generate two degraded images with pixel sizes of 20 and $30 \mathrm{~m}$. The increase in pixel size from 10 to 20 or $30 \mathrm{~m}$ did not significantly affect the classification accuracy for the five classifiers. However, the inclusion of the SWIR band significantly improved the classification accuracy compared with the use of the three VNIR bands only. For the maximum classification, the overall accuracy values without the SWIR band were $82.0 \%, 84.0 \%$ and $84.4 \%$ for the $10-, 20-$ and $30-\mathrm{m}$ images, respectively, compared with the overall accuracy values of $91.0 \%, 90.6 \%$ and $89.6 \%$ for the respective images with the SWIR bands. Sharma et al. ${ }^{[56]}$ found that the inclusion of the mid-infrared bands (bands 5 and 7) in Landsat TM data led to improvement in crop classification.

This study was one of the first evaluations of SPOT 5 satellite imagery for crop identification. Considering the image cost and weather constraints, it is more effective to use single-date SPOT 5 images for crop identification if the majority of the crops can be covered on a single-date image in a region; otherwise multi-date images may be necessary. The approaches and methods presented in this study can be useful for different crops in other regions. More research is needed to evaluate this type of imagery and compare it with other types of remote sensing data for crop identification and other applications.

\subsection{Example 2: QuickBird imagery for crop yield estima- tion}

Yang et al. ${ }^{[35,36]}$ compared QuickBird satellite imagery with airborne multispectral imagery for mapping plant growth and yield patterns within grain sorghum and cotton fields. Yang et al. ${ }^{[4]}$ also evaluated SPOT 5 satellite imagery to estimate crop yield. In this example, the work on the comparison of QuickBird and airborne imagery for mapping grain sorghum yield is presented. A QuickBird image scene covering a cropping area in south Texas was acquired in the 2003 growing season. The spatial resolution of the image was $2.8 \mathrm{~m}$ and the radiometric resolution was 11 bits. Airborne CIR images were collected using a three-camera imaging system. The airborne system consisted of three digital charge coupled device cameras that were equipped with a green $(555-565 \mathrm{~nm})$ filter, a red $(625-635 \mathrm{~nm})$ filter and a NIR $(845-857 \mathrm{~nm})$ filter, respectively. The three bands were combined to produce 8-bit CIR images with $1280 \times 1024$ pixel resolution. Grain yield data were collected using a PF3000 yield monitor (Ag Leader Technology, Ames, IA, USA).

Figure 2 shows the QuickBird CIR composite image and the airborne CIR image for a $20-\mathrm{hm}^{2}$ field in the imaging area. The pixel size for the airborne image was $0.92 \mathrm{~m}$, about a third of the QuickBird pixel size. Both the QuickBird and airborne images revealed distinct plant growth patterns within the field. The QuickBird image was taken at the bloom stage of the plant development (May $15)$, shortly after the peak growth for grain sorghum. The airborne image was taken 15 days later when the plants were primarily at the soft-dough stage. Despite the difference in plant growth stages and pixel size (2.8 vs. $0.92 \mathrm{~m}$ ), both images look fairly similar.

Correlation analysis between yield and vegetation indices (band ratios and normalized differences) at different pixel sizes showed that the band ratio NIR/ green provided best $r$-values for both types of imagery and that $r$-values tended to increase with pixel size. For the airborne imagery, the best $r$-values was 0.78 at the original pixel size $(0.92 \mathrm{~m}), 0.81$ at $2.8 \mathrm{~m}$ (QuickBird pixel size), and 0.85 at $8.4 \mathrm{~m}$ (close to harvest swath). For the QuickBird image, the best $r$-values was 0.83 at $2.8 \mathrm{~m}$ and 0.88 at $8.4 \mathrm{~m}$. Figure 3 shows the scatter plots and linear regression lines between grain sorghum yield and the band ratio NIR/green derived from the QuickBird image and the airborne image. Grain yield was significantly positively 
(a)

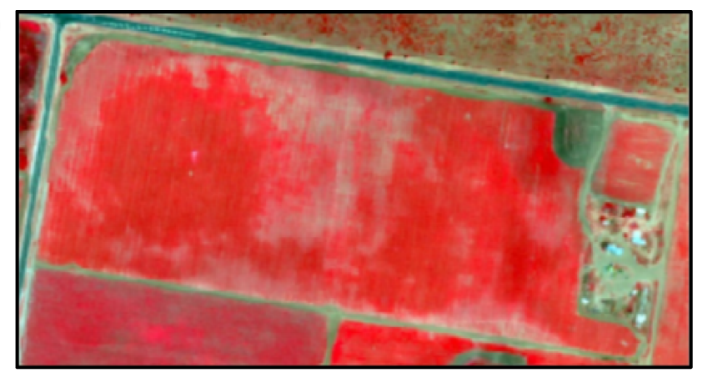

$0 \quad 100 \quad 200 \quad 300 \mathrm{~m}$ (b)

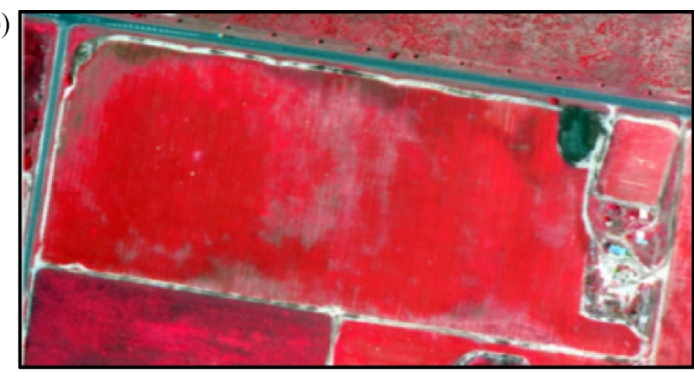

$\stackrel{N}{\AA}$

Fig. 2 QuickBird satellite color-infrared image (May 15, 2003) (a) and airborne color-infrared image (May 30, 2003) (b) for a 20-hm² grain sorghum field in south Texas, USA in 2003
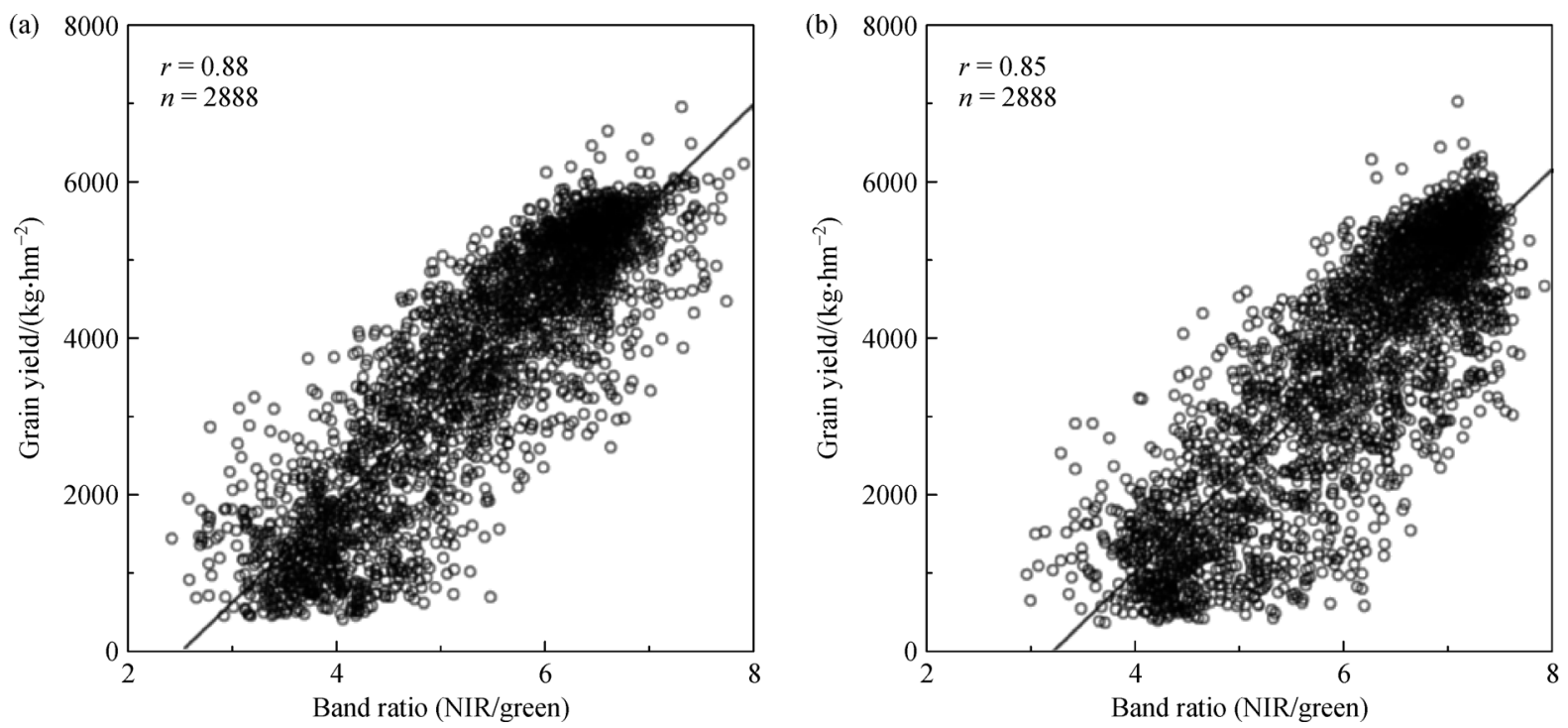

Fig. 3 Scatter plots and linear regression lines between grain sorghum yield and band ratio (NIR/green) derived from QuickBird satellite image (a) and airborne image (b) for a $20-\mathrm{hm}^{2}$ grain sorghum field in south Texas, USA in 2003

related to the band ratio.

Based on stepwise regression analysis at the 8.4-m resolution, the airborne image explained $77 \%$ of the variability in yield with all three bands, while the QuickBird image explained $80 \%$ of the variability with the green, red and NIR bands and $81 \%$ of the variability with all four bands. Although the QuickBird image had slightly higher $R^{2}$ values than the airborne image, both types of imagery accounted for essentially the same amount of yield variability, indicating that the QuickBird imagery is as effective as the airborne imagery for yield estimation.

\subsection{Example 3: GeoEye-1 imagery for crop disease detection}

To illustrate how high resolution satellite imagery can be used for site-specific crop management, the work on cotton root rot is used as an example. Cotton root rot, caused by the soilborne fungus Phymatotrichopsis omnivora, is a destructive disease that has affected the cotton industry for over a century. Not until 2015 was the commercial Topguard Terra fungicide registered to control the disease. Historical airborne images taken from infected cotton fields have demonstrated that cotton root rot tends to occur in the same general areas within fields over recurring years $^{[21]}$. The spatial nature of cotton root rot, its highly visible damage, and its annual reoccurrence in the same areas make it an excellent candidate for site-specific management. The infestation patterns within fields can generally be predicted based on historical remote sensing imagery.

Yang et al. ${ }^{[57]}$ demonstrated how site-specific fungicide application could be implemented based on historical airborne and satellite images and variable rate technology for site-specific management of cotton root rot. Figure 4 shows a GeoEye-1 CIR image acquired on July 27, 2009 for a $98-\mathrm{hm}^{2}$ cotton field infested with cotton root rot, a 
(a)

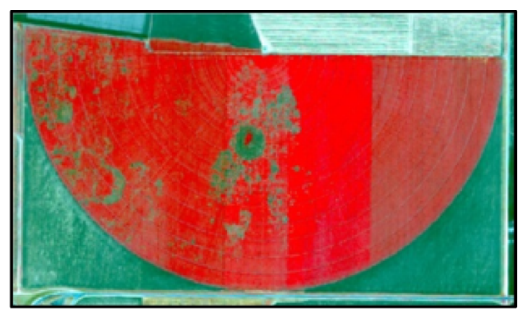

(b)

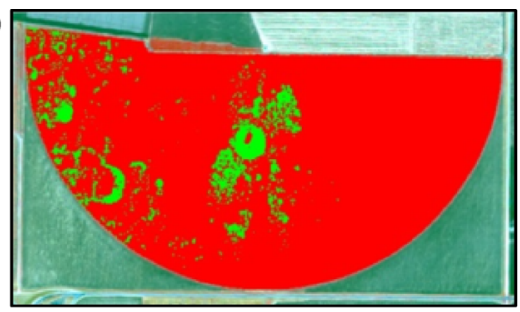

0
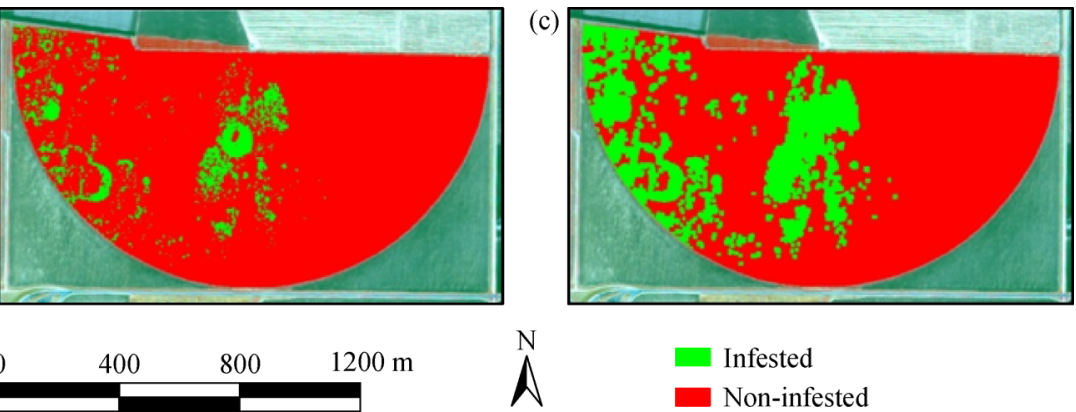

Infested

Non-infested

Fig. 4 GeoEye-1 satellite image (a), corresponding two-zone classification map (b), and prescription map (c) with a 5-m buffer for a $98-\mathrm{hm}^{2}$ cotton field infested with cotton root rot near Edroy, TX, USA

corresponding two-zone image classification map and a two-zone prescription map. On the CIR image, infested areas are dark green, while the non-infested areas are red. A field boundary or AOI was defined for the field and a normalized difference vegetation index image was created within the AOI. This vegetation index image was then classified into infested and non-infested zones using unsupervised classification.

Approximately $8 \%$ of the field was infested based on the classification map. To accommodate the potential expansion and temporal variation of the disease, buffer zones around the infested areas should be added as part of the treatment areas. With a 5-m buffer added to the infested areas, about $23 \%$ of the field (green areas) needs to be treated. The prescription map can be loaded into a variable rate control system mounted on a tractor for site-specific application of Topguard Terra fungicide. Considering that the cost of the fungicide is about $124 \mathrm{USD} \cdot \mathrm{hm}^{-2}$ at full application rate and, if only $23 \%$ of the field is treated, the savings from reduced fungicide use would be $77 \%$ or about $9357 \mathrm{USD}\left(124 \mathrm{USD} \cdot \mathrm{hm}^{-2} \times 98 \mathrm{hm}^{2} \times 77 \%\right)$ per year. Therefore, site-specific management of this disease holds significant promise to increase efficiency and reduce cost.

\section{Challenges and future directions}

Remote sensing applications in precision agriculture have been steadily increasing in the last two decades due to improvements in spatial, spectral and temporal resolutions of airborne and satellite remote sensors. More recently, unmanned aircraft systems (UAS) have become a popular remote sensing platform to fill the gap between manned and ground-based platforms due to their low cost, lowflying altitude for high spatial resolution imagery, and ease of operation. Although tremendous progress has been made in the development of high resolution satellite sensors since 1999, some challenges remain for the selection and processing of high resolution satellite imagery for precision agriculture applications. Growers are generally aware of the availability of satellite imagery in addition to airborne imagery, but most of them do not keep up with the various types of satellite sensors in this fast-changing market. They are not clear which type of imagery to select and how to order new or archived images for their particular applications. Therefore, image providers and vendors need to develop better instructions for growers and customers to enable them to select and order image products.

Another challenge is timely acquisition and delivery of task-ordered images. Although many satellite sensors have a revisit time of 1-5 days, the actual image acquisition time can vary greatly, depending on the local weather conditions and the competition with other customers in the similar geographic area. As more satellite sensors become available, customers are able to order from more than one satellite sensor owned by a company. This will increase the chances of obtaining timely images. Meanwhile, numerous companies are providing airborne imaging services, which have the advantage of taking higher resolution imagery anytime weather permits. However, unlike satellite imagery that is typically available anywhere on the earth, airborne imagery can only be acquired in areas where airborne imaging services are provided. Although UASbased remote sensing is growing quickly for precision agriculture, their relative small ground coverage and safety concerns may restrict their use for some applications.

Other challenges are related to the processing and conversion of images into useful maps or information. Although numerous publications on image processing are available in the literature, there are currently no standardized procedures and software available for converting images to classification maps, vegetation index maps, and prescription maps especially for precision agriculture. Software used for image processing and analysis comes in different capabilities, complexities, and prices, and growers may have difficulty selecting appropriate software for image processing. Furthermore, delivered images are usually georeferenced, but their positional accuracy varies. For most applications, the delivered images can be directly used for processing and analysis. For applications that require time series image data, however, radiometric 
calibration is important, but standard, accepted procedures for retrieving reflectance and temperature data from various types of images are still lacking.

Therefore, it is necessary for researchers and extension specialists to develop practical guides for growers and other end-users so that they will be able to use available techniques and software to convert imagery to proper maps for precision agriculture applications. Users experienced with GIS and image processing should be able to use appropriate software to perform image analysis with the help of software documentation and tutorials. Users new to GIS and image analysis, but with good computer skills and experiences, may be able to learn to use the software to perform basic image analysis. After all, image processing is a specialized field and requires more advanced computer skills and a basic understanding of the techniques involved. If this is not practical for some growers, they can always use a commercial image processing service to process their images and create relevant maps. Some agricultural dealerships are providing precision agriculture services for image acquisition, prescription map creation and variable rate application.

Although all types of remote sensing platforms and imaging systems are available, various factors have to be considered in order to decide which is most appropriate for a particular application, including the size of the area to be mapped, complexity of associated crop types, and time and cost constraints. Airborne imaging systems offer some advantages, including the immediate availability for realtime assessment and the flexibility to change filters for desired wavelengths and bandwidths. High resolution satellite systems can cover large areas with relatively fine spatial resolution. Satellite imagery can be cost-effective for large geographic areas, but it may not be available when it is needed for time-sensitive applications due to weather conditions, satellite orbits, competition for images at the same time with other customers. UAS have the potential as a versatile remote sensing platform, but there are still many restrictions on the use of UAS for commercial applications. Imagery acquired from different platforms (i.e., ground-based, UAS, manned aircraft and satellites) should also be evaluated for their suitability and effectiveness for different precision agriculture applications.

Multispectral imagery with four standard spectral bands (i.e., blue, green, red and NIR) is sufficient for most precision agriculture applications, but additional bands in red edge, SWIR, thermal wavelengths may be useful for monitoring vegetation health, water stress and canopy temperature. Hyperspectral imaging sensors can be used to detect or distinguish spectrally similar plant species or symptoms. Other sensor technologies such as fluorescence and lidar need to be further investigated. As a costeffective alternative, imaging systems based on consumergrade cameras have a great potential, but more accurate camera modification methods are needed to improve the spectral fidelity of the modified bands.

Many precision agriculture activities have already benefited from applications of remote sensing technology. As growers gain more experience and confidence in this technology, they will incorporate it in their crop production practices. Precision agriculture involves the integration of data acquisition, data analysis, decision making and variable rate application. Remote sensing is just an integral part of the process. Future efforts should be focused on the development of education and technology sharing networks among image providers, researchers, extension specialists, agricultural dealerships and growers by including all clients in the process. With the advances in imaging sensor technology, remote sensing imagery will be available at higher resolution, shorter revisit time, and lower prices than ever before. This will present growers with great opportunities to integrate this information into their production systems for increased efficiency and profitability.

Disclaimer Mention of trade names or commercial products in this article is solely for the purpose of providing specific information and does not imply recommendation or endorsement by the US Department of Agriculture (USDA). The USDA is an equal opportunity provider and employer.

Compliance with ethics guidelines Chenghai Yang declares that he has no conflict of interest or financial conflict to disclose.

This article is a review and does not contain any studies with human or animal subjects performed by the author.

\section{References}

1. Bramley $R$ G V. Lessons from nearly 20 years of precision agriculture research, development, and adoption as a guide to its appropriate application. Crop \& Pasture Science, 2009, 60(3): 197217

2. Srinivasan A. Handbook of precision agriculture: principles and applications. Boca Raton, Florida: CRC Press, 2009

3. Robertson M J, Llewellyn R S, Mandel R, Lawes R, Bramley R G $\mathrm{V}$, Swift L, Metz N, O’Callaghan C. Adoption of variable rate technology in the Australian grains industry: status, issues and prospects. Precision Agriculture, 2011, 13: 181-199

4. Zhang Q. Precision agriculture technology for crop farming. Boca Raton, Florida: CRC Press, 2016

5. Schimmelpfennig D, Ebel R. On the doorstep of the information age: recent adoption of precision agriculture. Publication No. EIB80. Washington, DC: U.S. Department of Agriculture, Economic Research Service, 2011

6. Yang C, Sui R, Lee W S. Precision agriculture in large-scale mechanized farming. In: Zhang $Q$, ed. Precision agriculture technology for crop farming. Boca Raton, Florida: CRC Press, 2016, 177-211

7. Mulla D J. Twenty five years of remote sensing in precision agriculture - key advances and remaining knowledge gaps. Biosystems Engineering, 2013, 114(4): 358-371

8. Morain S A, Williams D L. Wheat production estimates using 
satellite images. Agronomy Journal, 1975, 67(3): 361-364

9. Ryerson R A, Dobbins R N, Thibault C. Timely crop area estimates from Landsat. Photogrammetric Engineering and Remote Sensing, 1985, 51: 1735-1743

10. Büttner G, Csillag F. Comparative study of crop and soil mapping using multitemporal and multispectral SPOT and Landsat Thematic Mapper data. Remote Sensing of Environment, 1989, 29(3): 241249

11. Oettera D R, Cohenb W B, Berterretchea M, Maierspergera T K, Kennedya R E. Land cover mapping in an agricultural setting using multiseasonal Thematic Mapper data. Remote Sensing of Environment, 2001, 76(2): 139-155

12. Murakami T, Ogawa S, Ishitsuka N, Kumagai K, Saito G. Crop discrimination with multitemporal SPOT/HRV data in the Saga Plains, Japan. International Journal of Remote Sensing, 2001, 22(7): 1335-1348

13. Mausel P W, Everitt J H, Escobar D E, King D J. Airborne videography: current status and future perspectives. Photogrammetric Engineering and Remote Sensing, 1992, 58: 1189-1195

14. King D J. Airborne multispectral digital camera and video sensors: a critical review of systems designs and applications. Canadian Journal of Remote Sensing, 1995, 21(3): 245-273

15. Moran M S, Inoue Y, Barnes E M. Opportunities and limitations for image-based remote sensing in precision crop management. Remote Sensing of Environment, 1997, 61(3): 319-346

16. Barnes E M, Sudduth K A, Hummel J W, Lesch S M, Corwin D L, Yang C, Daughtry C S T, Bausch W C. Remote- and ground-based sensor techniques to map soil properties. Photogrammetric Engineering and Remote Sensing, 2003, 69(6): 619-630

17. Varvel G E, Schlemmer M R, Schepers J S. Relationship between spectral data from an aerial image and soil organic matter and phosphorus levels. Precision Agriculture, 1999, 1(3): 291-300

18. Yang C, Everitt J H. Relationships between yield monitor data and airborne multidate multispectral digital imagery for grain sorghum. Precision Agriculture, 2002, 3(4): 373-388

19. Inman D, Khosla R, Reich R, Westfall D G. Normalized difference vegetation index and soil color-based management zones in irrigated maize. Agronomy Journal, 2008, 100(1): 60-66

20. Backoulou G F, Elliott N C, Giles K L, Mirik M. Processed multispectral imagery differentiates wheat crop stress caused by greenbug from other causes. Computers and Electronics in Agriculture, 2015, 115: 34-39

21. Yang C, Odvody G N, Thomasson J A, Isakeit T, Nichols R L. Change detection of cotton root rot infection over 10-year intervals using airborne multispectral imagery. Computers and Electronics in Agriculture, 2016, 123: 154-162

22. Cohen Y, Alchanatis V, Saranga Y, Rosenberg O, Sela E, Bosak A. Mapping water status based on aerial thermal imagery: comparison of methodologies for upscaling from a single leaf to commercial fields. Precision Agriculture, 2017, 18(5): 801-822

23. Bajwa S G, Tian L F. Soil fertility characterization in agricultural fields using hyperspectral remote sensing. Transactions of the ASAE. American Society of Agricultural Engineers, 2005, 48(6): 2399-2406

24. Goel P K, Prasher S O, Landry J A, Patel R M, Viau A A, Miller J R. Estimation of crop biophysical parameters through airborne and field hyperspectral remote sensing. Transactions of the ASAE (American Society of Agricultural Engineers), 2003, 46(4): 12351246

25. Zarco-Tejada P J, Ustin S L, Whiting M L. Temporal and spatial relationships between within-field yield variability in cotton and high-spatial hyperspectral remote sensing imagery. Agronomy Journal, 2005, 97(3): 641-653

26. Yang C, Everitt J H, Bradford J M. Airborne hyperspectral imagery and linear spectral unmixing for mapping variation in crop yield. Precision Agriculture, 2007, 8(6): 279-296

27. Fitzgerald G J, Maas S J, Detar W R. Spidermite detection in cotton using hyperspectral imagery and spectral mixture analysis. Precision Agriculture, 2004, 5: 275-289

28. Kumar A, Lee W S, Ehsani M R, Albrigo L G, Yang C, Mangan R L. Citrus greening disease detection using aerial hyperspectral and multispectral imaging techniques. Journal of Applied Remote Sensing, 2012, 6(1): 063542

29. Li H, Lee W S, Wang K, Ehsani R, Yang C. Extended spectral angle mapping (ESAM) for citrus greening disease detection using airborne hyperspectral imaging. Precision Agriculture, 2014, 15 (2): 162-183

30. MacDonald S L, Staid M, Staid M, Cooper M L. Remote hyperspectral imaging of grapevine leafroll-associated virus 3 in cabernet sauvignon vineyards. Computers and Electronics in Agriculture, 2016, 130: 109-117

31. Johnson L F, Roczen D E, Youkhana S K, Nemani R R, Bosch D F. Mapping vineyard leaf area with multispectral satellite imagery. Computers and Electronics in Agriculture, 2003, 38(1): 33-44

32. Dobermann A, Ping J L. Geostatistical integration of yield monitor data and remote sensing improves yield maps. Agronomy Journal, 2004, 96(1): 285-297

33. Sullivan D G, Shaw J N, Rickman D. IKONOS imagery to estimate surface soil property variability in two Alabama physiographies. Soil Science Society of America Journal, 2005, 69(6): 17891798

34. Ping J L, Ferguson R B, Dobermann A. Site-specific nitrogen and plant density management in irrigated maize. Agronomy Journal, 2008, 100(4): 1193-1204

35. Yang C, Everitt J H, Bradford J M. Comparison of QuickBird satellite imagery and airborne imagery for mapping grain sorghum yield patterns. Precision Agriculture, 2006, 7(1): 33-44

36. Yang C, Everitt J H, Bradford J M. Evaluating high resolution QuickBird satellite imagery for estimating cotton yield. Transactions of the ASABE, 2006, 49(5): 1599-1606

37. Yang C, Everitt J H, Fletcher R S, Murden D. Using high resolution QuickBird imagery for crop identification and area estimation. Geocarto International, 2007, 22(3): 219-233

38. Franke J, Menz G. Multi-temporal wheat disease detection by multispectral remote sensing. Precision Agriculture, 2007, 8(3): 161-172

39. Shou L, Jia L, Cui Z, Chen X, Zhang F. Using high-resolution satellite imaging to evaluate nitrogen status of winter wheat. Journal of Plant Nutrition, 2007, 30(10): 1669-1680

40. Bausch W C, Halvorson A D, Cipra J. QuickBird satellite and ground-based multispectral data correlations with agronomic parameters of irrigated maize grown in small plots. Biosystems Engineering, 2008, 101(3): 306-315 
41. Song X, Wang J, Huang H, Liu L, Yan G, Pu R. The delineation of agricultural management zones with high resolution remotely sensed data. Precision Agriculture, 2009, 10(6): 471-487

42. Bausch W C, Khosla R. QuickBird satellite versus ground-based multi-spectral data for estimating nitrogen status of irrigated maize. Precision Agriculture, 2010, 11(3): 274-290

43. Santoso H, Gunawan T, Jatmiko R H, Darmosarkoro W, Minasny B. Mapping and identifying basal stem rot disease in oil palms in North Sumatra with QuickBird imagery. Precision Agriculture, 2011, 12 (2): 233-248

44. De Castro A I, Lopez-Granados F, Jurado-Exposito M. Broad-scale cruciferous weed patch classification in winter wheat using QuickBird imagery for in-season site-specific control. Precision Agriculture, 2013, 14(4): 392-413

45. Yang C, Everitt J H, Bradford J M. Evaluating high resolution SPOT 5 satellite imagery to estimate crop yield. Precision Agriculture, 2009, 10(4): 292-303

46. Yang C, Everitt J H, Murden D. Using high resolution SPOT 5 multispectral imagery for crop identification. Computers and Electronics in Agriculture, 2011, 75: 347-354

47. Söderström M, Borjesson T, Pettersson C G, Nissen K, Hagner O. Prediction of protein content in malting barley using proximal and remote sensing. Precision Agriculture, 2010, 11(6): 587-599

48. Ghobadifar F, Aimrun W, Jebur M N. Development of an early warning system for brown planthopper (BPH) (Nilaparvata lugens) in rice farming using multispectral remote sensing. Precision Agriculture, 2016, 17(4): 377-391

49. Yuan L, Pu R, Zhang J, Wang J, Yang H. Using high spatial resolution satellite imagery for mapping powdery mildew at a regional scale. Precision Agriculture, 2016, 17(3): 332-348
50. Wagner P, Hank K. Suitability of aerial and satellite data for calculation of site-specific nitrogen fertilisation compared to ground based sensor data. Precision Agriculture, 2013, 14(2): 135-150

51. Magney T S, Eitel J U H, Vierling L A. Mapping wheat nitrogen uptake from RapidEye vegetation indices. Precision Agriculture, 2017, 18(4): 429-451

52. Bu H, Sharma L K, Denton A, Franzen D W. Comparison of satellite imagery and ground-based active optical sensors as yield predictors in sugar beet, spring wheat, corn, and sunflower. Agronomy Journal, 2017, 109(1): 299-308

53. Gomez-Candon D, Lopez-Granados F, Caballero-Novella J J, PenaBarragan J M, García-Torres L. Understanding the errors in input prescription maps based on high spatial resolution remote sensing images. Precision Agriculture, 2012, 13(5): 581-593

54. Caturegli L, Casucci M, Lulli F, Grossi N, Gaetani M, Magni S, Bonari E, Volterrani M. GeoEye-1 satellite versus ground-based multispectral data for estimating nitrogen status of turfgrasses. International Journal of Remote Sensing, 2015, 36(8): 2238-2251

55. Li X, Lee W S, Li M, Ehsani R, Mishra A R, Yang C, Mangan R L. Feasibility study on Huanglongbing (citrus greening) detection based on WorldView-2 satellite imagery. Biosystems Engineering, 2015, 132: 28-38

56. Sharma S A, Bhatt H P, Ajai. Oilseed crop discrimination: selection of optimum bands and role of middle infrared. ISPRS Journal of Photogrammetry and Remote Sensing, 1995, 50(5): 25-30

57. Yang C, Odvody G N, Thomasson J A, Isakeit T, Minzenmayer R R, Drake D R, Norton R, Barnes E M, Nichols R L. Site-specific management of cotton root rot using airborne and satellite imagery and variable rate technology. Cary, North Carolina: Cotton Incorporated, 2017 